\title{
Hydrophilic Polymers Containing Chiral Nucleic Acid Base Pendants as Polynucleotide Analogs
}

\section{C.G. Overberger, K.A. Brandt, S. Kikyotani and Adriane G. Ludwick*}

Department of Chemistry and the Macromolecular Research Center, The University of Michigan, Ann Arbor, Ml 48109, USA

\section{Dedicated to Prof. Dragutin Fles on the occasion of his 60th birthday}

\section{SUMMARY}

A survey of our recent work on synthetic polynucleotide analogs is given. Propionic acid and 3-methyl butyric acid derivatives substituted in the 2-position with nucleic acid bases have been used as chiral pendants for attachment to hydrophilic polyamine backbones. Hindered rotation about the amide bonds formed promotes a base-stacked structure as shown by ultraviolet hypochromic effects versus model compounds. If the pendant has been resolved, an optically active polymer results which may be studied by circular dichroism (CD). Thus, poly (ethylenimine) containing the (-)-2-(thymin-1-yl)propionyl group as the grafted pendant showed exciton coupling of the $\mathrm{B}_{2 \mathrm{u}}$ transition of the base chromophores in the $C D$, as observed in polynucleotides. This implies at least a local helical order in the stacking. The biological activity of such structures is briefly discussed.

\section{INTRODUCT ION}

Since the late 1950 's, a myriad of synthetic polynucleotide models have been made (SHOMSHTEIN \& GILLER, 1976; JONES, 1979; TAKEMOTO and INAKI, 1981); a number have been studied in aqueous solution. Notable among backbone-modified systems is the elegant work on poly(9-vinyl adenine) and poly(l-vinyl uracil) (KAYE and CHOU, 1973, 1975; PITHA, 1977). These polymers interact with natural polynucleotides; the former inhibits the replication of Friend leukemia virus in mice. In order to study such analogs in aqueous environments and to maximize the potential for biological activity (LUDWICK and OVERBERGER, 1980), we have designed hydrophilic systems of high structural order. Again in analogy with natural polynucleotides, we have placed a chiral center adjacent to the chromophore in our systems. This permits study by $C D$ in addition to the usual UV hypochromic effects. Three linear polymer backbones have been used: poly (ethy lenimine) (PEI), poly (vinylamine) (PVam), and poly (dehydroalanine) (PDA). In the first two cases, 
polymer grafting reactions were used to incorporate nucleic acid base moieties; in the latter case, freeradical polymerization of vinyl monomers gave high molecular weight analogs.

\section{RESULTS AND DISCUSSION}

\section{Poly (ethylenimine) Analogs}

Linear PEI's of various molecular weights have been used for grafting nucleic acid base derivatives as summarized in Scheme 1. The PEI's were obtained either synthetically (SAEGUSA et al., 1972) or by acidic

hydrolysis of linear poly(N-propanoylethylenimine) from Dow Chemical co.

\section{Scheme 1. Nucleic Acid Analogs Based on PEI}
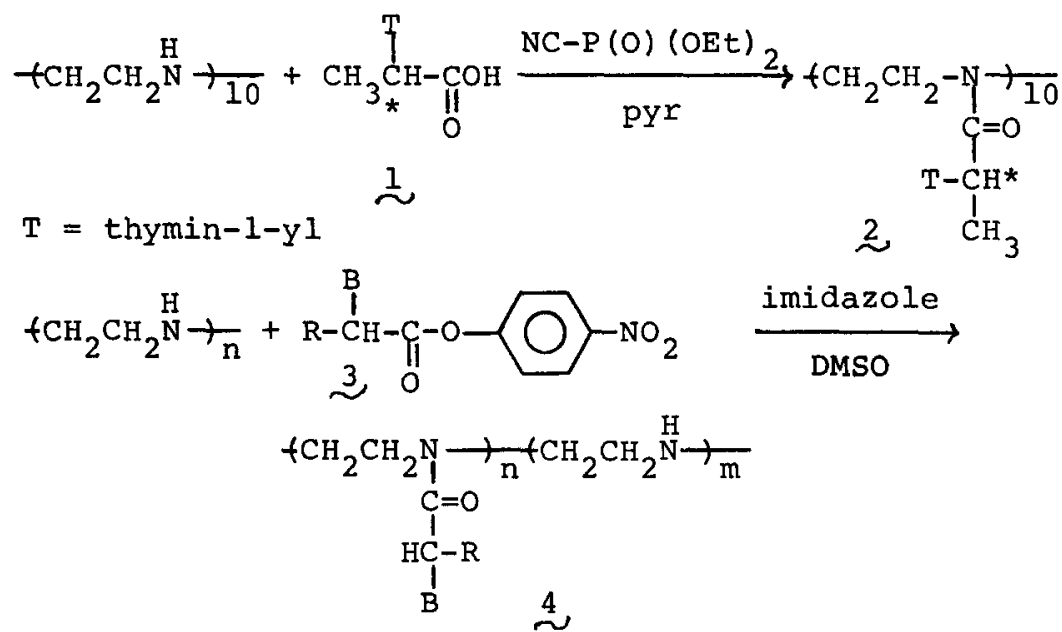

\begin{tabular}{lllll}
$\#$ & \multicolumn{1}{c}{$\mathrm{R}$} & \multicolumn{1}{c}{ B } & \multicolumn{1}{c}{ Composition } \\
\hline $4 \mathrm{a}$ & $\mathrm{CH}_{3}$ & adenin-9-yl & $\mathrm{n}+\mathrm{m}=10$, & $\mathrm{n}=5.7$ \\
$4 \mathrm{~b}$ & $\mathrm{CH}_{3}$ & thymin-1-yl & $\mathrm{n}=10$, & $\mathrm{m}=0$ \\
$4 \mathrm{C}$ & $\mathrm{CH}_{3}$ & $6-$ acetyl adenin-9-yl & $\mathrm{n}+\mathrm{m}=30$, & $\mathrm{n}>27$ \\
$4 \mathrm{~d}$ & $\mathrm{CH}_{3}$ & $6-\operatorname{acetyl}$ adenin-9-yl & $\mathrm{n}+\mathrm{m}=100$, & $\mathrm{n}>90$ \\
$4 \mathrm{e}$ & $\mathrm{CH}_{3}$ & thymin-1-yl & $\mathrm{n}=30$ or $100, \mathrm{~m}=0$ \\
$4 \mathrm{f}$ & $\mathrm{CH}_{3}$ & uracil-1-yl & $\mathrm{n}=30$ or $100, \mathrm{~m}=0$ \\
$4 \mathrm{~g}$ & $\left(\mathrm{CH}_{3}\right)_{2} \mathrm{CH}$ & thymin-1-yl & $\mathrm{n}=30$ or $100, \mathrm{~m}=0$
\end{tabular}


Grafting was carried out using either a direct approach with diethyl phosphocyanidate in the case of optically active 1 or via racemic p-nitrophenyl active esters 3 , giving analogs 2 and 4 . These polymers indicate similarity to natural nucleic acids; significant hypochromicity vs. monomer models was observed for all of the compounds in aqueous solution (e.g., 45.4\% for $4 \mathrm{a}$ and $36.8 \%$ for $4 \mathrm{~b}$ ) as well as for the dimer models made from sym-dimethylethylenediamine (OVERBERGER and MORISHIMA, 1980a; MORISHIMA and OVERBERGER, 1979).

Although 2 or $4 \mathrm{~b}$ and $4 \mathrm{a}$ showed complementary base pair interactions in continuous variation mixing experiments, the low percent graft of $4 \mathrm{a}$ make elucidation of the nature of this complex difificult. To improve the percent graft, protection of the $6-\mathrm{NH}_{2}$ group of adenine was carried out by the following route:<smiles>CCOC(=O)C(C)n1cnc2c(N)ncnc21</smiles>

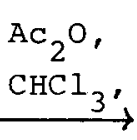

$\Delta$<smiles>CC(=O)Nc1ncnc2c1ncn2C(C)C(C)=O</smiles>

$(82 \%)$<smiles>C[14CH2]c1ncnc2c1ncn2[C@@H](C)C(=O)O</smiles>

$(70 \circ)$

1 eq. $\mathrm{K}_{2} \mathrm{CO}_{3}$,

$\underset{45^{\circ}}{\mathrm{H}_{2} \mathrm{O}}$

Compound 5 could be grafted much more cleanly giving highly water-soluble $4 \mathrm{c}$ and $4 \mathrm{~d}$. Deprotection is effected in dilute aqueous $\mathrm{HCl}$. Experiments are in progress to study the interactions of these polymers with 4 e. When the pendant is optically active as in 2 the $C \bar{D}$ spectrum revealed splitting of the $B_{2 u}$ transition by exciton interaction of the stacked bases, implying a helical order (OVERBERGER and MORISHIMA, 1980b). Placing an L-proline spacer group between the backbone and the propionyl moiety permitted stacking, but destroyed any screw sense (OVERBERGER and MORISHIMA, 1980c).

Uracilyl polymers $4 \mathrm{f}$ and polymers $4 \mathrm{~g}$, derivatives of 3-methyl butyric acid, have been synthesized and examined spectroscopically (LUDWICK and OVERBERGER). 
The bulky $R$ group of the latter favors trans amide bonds but may also sterically impede stacking. NMR shows similar conformational populations, whether $\mathrm{R}=$ $\mathrm{CH}_{3}$ or $\left(\mathrm{CH}_{3}\right)_{2} \mathrm{CH}$, and hypochromicities are comparable. Hypochromicities decrease as $\mathrm{pH}$ increases due to electrostatic repulsion between the charged rings, but increasing the ionic strength even at high $\mathrm{pH}$ 's increased the hypochromicity. Studies in $\mathrm{DMSO} / \mathrm{H}_{2} \mathrm{O}$ solutions showed increased base-stacking in the more aqueous solvents; for polymer $4 \mathrm{f}$ with $\mathrm{n}=100$, a marked increase was noted. Since significant activity against influenza A/Victoria/75 was observed in 68 aqueous DMSO solution for $4 \mathrm{f}$ when $\mathrm{n}=100$ (but not when $\mathrm{n}=30$ ), water may play some role in the ordering of $4 \mathrm{f}$ and similar polymers. Polymer $4 \mathrm{f}$ and its monomer model also interact with poly $A$ in TRIS buffer solutions. Detailed biological testing of 4 and the synthesis of higher molecular weight grafts $\bar{w} i l l$ be carried out; synthesis of optically active 4 will permit further $C D$ studies. Similar chemistry is proving useful for analogous guanine, cytosine, and carbazole derivatives.

\section{Poly (vinylamine) Analogs}

The grafting of compounds 3 to linear PVam of molecular weight 6,000 to $150,0 \overline{00}$ (prepared either by hydrolysis of poly (vinyl acetamide) or poly (vinyl-tbutyl carbamate) has proven to be more difficult than in the case of PEI. This may be due to the low solubility of PVam, which could be dissolved in DMF or DMSO only by adding an acidic compound such as 1-hydroxybenzotriazole. Under these homogeneous conditions, many peptide-coupling reagents gave high percent grafts, but caused severe racemization. Several sulfonic acid esters of hydroxybenzotriazoles (ITOH et al., 1978) however have proven effective in reactions of 1 to give monomer, dimer, and polymer models. These reağents gave good yields, high percent grafts, and little racemization in DMF with pyridine as base (Scheme 2). Treatment of 2,4-pentanedione with hydroxylamine gave the dioxime which was reduced and acidified yielding the dihydrochloride salt of 2,4-diaminopentane. Reaction of the separated meso, $(+)$ and $(-)$ stereoisomers of 2,4-diaminopentane (APPLETON and HALL, 1970) gave diastereomers 6 which are being separated by HPLC to give dimer models for syndiotactic, heterotactic, and isotactic 7 . Detailed spectroscopic studies on the effects of tacticity on the solution behavior of these systems are in progress.

\section{Poly(dehydroalanine) Analogs}

Although many polyanionic nucleic acid analogs have been made by copolymerization (HOFFMANN, 1979; MAGGIORA et al., 1977), few homopolymers of this type 


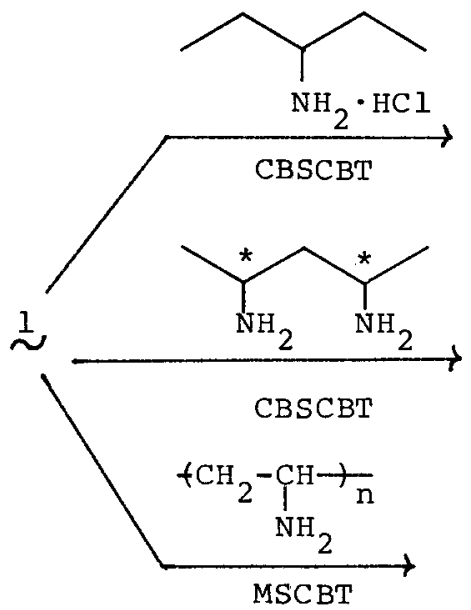

$\mathrm{T}=$ thymin- $1-\mathrm{yl}$

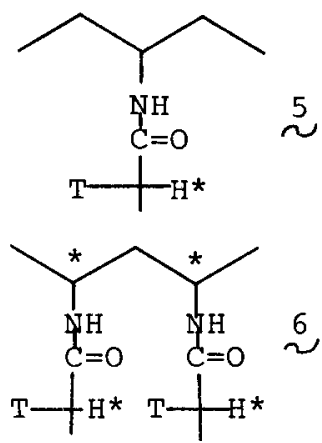

$(358)$

$\left(60 \frac{0}{6}\right)$

$(95 \%$

graft)

MSCBT = methanesulfony 1-4-chlorobenzotriazole

CBSCBT $=4$-chlorobenzenesulfonyl-4-chlorobenzotriazole

Scheme 2. Nucleic Acid Analogs Based on PVam.

have been reported. A homopolymer would have greater structural regularity, characteristic of polynucleotides, the negative charge should increase water solubility and might be important with respect to biological activity.

Recent work in the literature on water-soluble poly (N-acetyl dehydroalanine) (ASQUITH et al., 1978) led us to investigate this backbone. After a report on the use of $\beta$-chloroalanine methyl ester as a synthon for a dehydroalanine monomer appeared (MATHIAS, 1980), we found a modification applicable to our system, as shown in scheme 3 . The coupling conditions used in the PVam series formed the new amide bond; after removal of by-products, dehydrochlorination with $\mathrm{Et}_{3} \mathrm{~N}$ in EtoAc proceeded smoothly affording monomer 10, which could be hydrolyzed in base (PHOTAKI, 1963) to give the dehydroalanine monomer 11.

Both 10 and 11 polymerize readily to high molecular weight products 12 as indicated by spectral and viscosity data. polymer $12 \mathrm{~b}$ showed marked polyelectrolyte behavior in DMF, with a large increase in viscosity at high dilution. Solubility of the polymers is excellent: both are soluble in DMF and DMSO; 12a is soluble in TFE and $\mathrm{CHCl}_{3} / \mathrm{MeOH}$, while, most impor- 
Scheme 3. Nucleic Acid Analogs Based on PDA

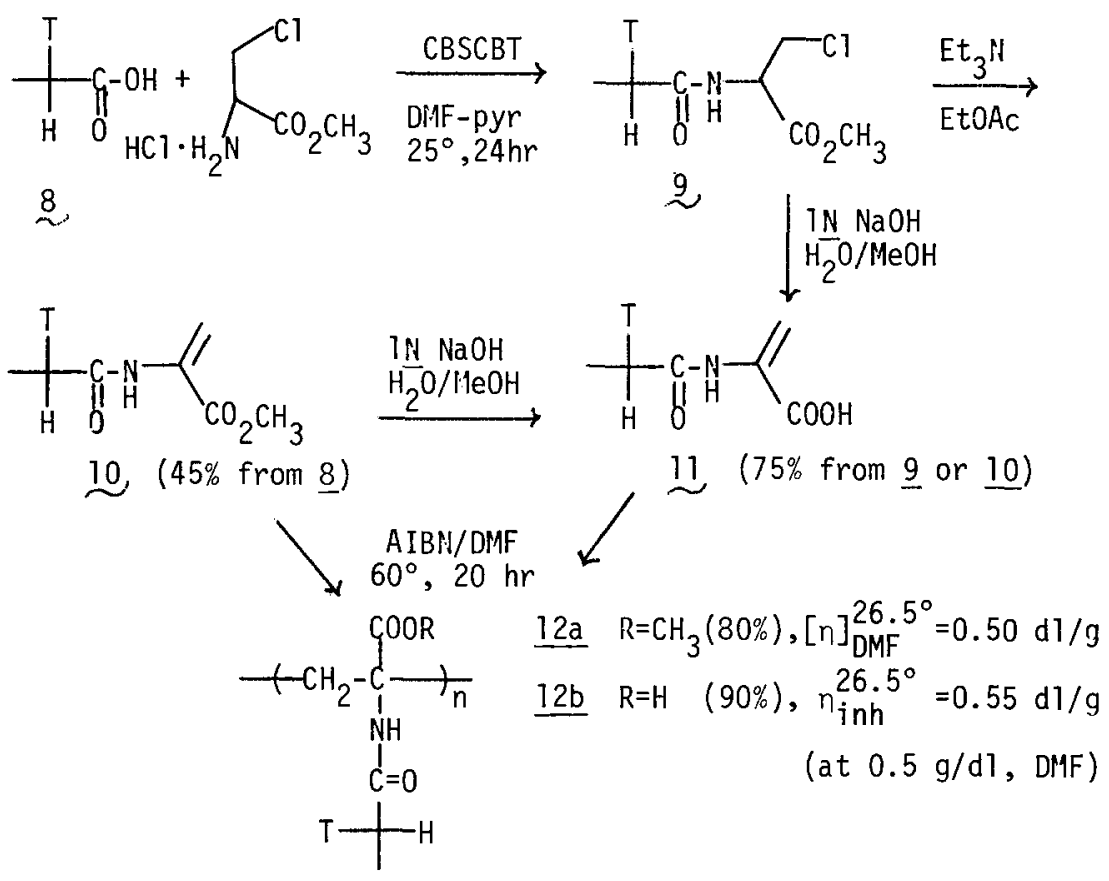

tantly, $12 b$ is very soluble in neutral water.

Monomer models $13 \mathrm{a}$ and $13 \mathrm{~b}$ were also synthesized:

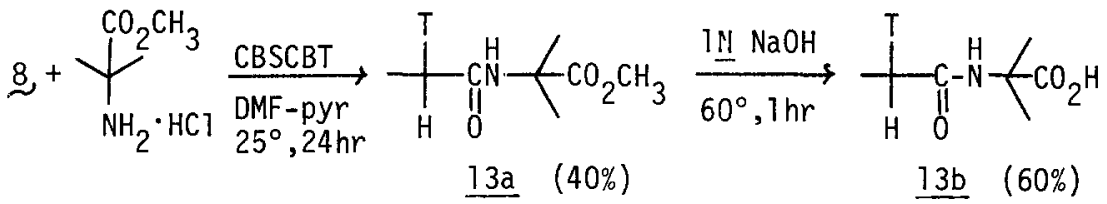

Significant UV hypochromicity is observed for 12 vs. 13 in aqueous solutions. The results in DMSO $/ \overline{\mathrm{H}_{2}} \mathrm{O}$ are shown in Figure 1. The behavior of $12 \mathrm{a}$ is in accord with the results obtained for $4 \mathrm{f}$ and $\overline{4 \mathrm{~g}}$, while $12 \mathrm{~b}$ shows the opposite trend. If $\overline{\overline{I 2 b}}$ is assumed to be mainly syndiotactic with trans amide bonds, then the maximum separation of ionized carboxyl groups expected in organic solvents would give a high degree of basestacking.

Further insight into the secondary structure of 12 should be provided by $C D$. Preliminary experiments have shown that by using optically active $8\left([\alpha]_{D}^{25^{\circ}}=-49^{\circ}\right.$ [TFE, $C=1]$ ), optically active 10 may be obtained and polymerized, yielding $12 \mathrm{a}$ with $[\bar{\alpha}]_{\mathrm{D}}^{2}{ }^{\circ}=-129^{\circ}(\mathrm{C}=1$, TFE). This polymer and polymer 2 exhibit similar CD spectra in TFE. Further work on these analogs and on 


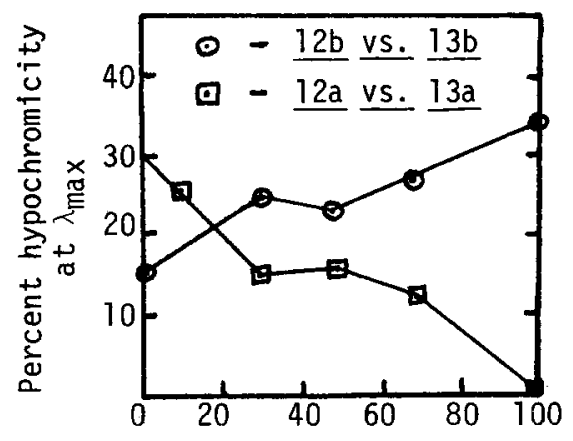

Volume percent DMSO in $\mathrm{DMSO} / \mathrm{H}_{2} \mathrm{O}$ solution Figure 1. Hypochromicity of 12 versus 13 in DMSO/H $\mathrm{H}_{2} \mathrm{O}$

the synthesis of dehydroalanine monomers containing other nitrogen heterocycles is in progress.

Acknowledgements: We gratefully acknowledge support from the Macromolecular Research Center at the University of Michigan (KAB) and the Sekisui Chemical Co. (SK). AGL is indebted to the National Institutes of Health (Grant 1 F34 6M06579-01) and the National

Science Foundation (Grant SPI 78-19121) for financial support while on leave from Tuskegee Institute.

\section{REFERENCES}

APPLETON, T.G. and HALL, J.R.: Inorg. Chem., 9, 1800 (1970)

ASQUITH, R.S., GARDNER, K.L., and YEUNG, K.W.: J.

Polym. Sci., Polym. Chem. Ed., 16, 3275 (1978)

HOFFMANN, S.: Z. Chem. , 7, 241 (1979)

ITOH, M., NOJIMA, H., NOTANI, J., HAGIWARA, D. and

TAKAI, K.: Bull. Chem. Soc. Jap., 51, 3320 (1978)

JONES, A.S.: Int. J. Biol. Macromol., 1, 194 (1979)

KAYE, H. and CHANG, S.-H.: J. Macromol. Sci.-Chem., A7(5), 1127 (19.73)

KAYE, H. and CHOU, H.J.: J. Polym. Sci., Polym. Phys. Ed. , 13, 477 (1975)

LUDNICK, A.G. and OVERBERGER, C.G.: Rev. Roum. Chim., 25(7), 1011 (1980)

LUDWICK, A.G. and OVERBERGER, C.G.: J. Polym. Sci., Polym. Chem. Ed., in press

MAGGIORA, L., BOGUSLAWSKI, S. and MERTES, M.: J. Med. Chem., 20, 1283 (1977) 
MATHIAS, L.: J. Polym. Sci., Polym. Lett. Ed., 18, 665 (1980)

MORISHIMA, Y. and OVERBERGER, C.G.: J. Macromol. Sci.Chem., Al3(5), 573 (1979)

OVERBERGER, C.G. and MORISHIMA, Y.: J. POIym. Sci.,

Polym. Chem. Ed., 18, 1247 (1980)a

OVERBERGER, C.G. and MORISHIMA, Y.: J. POlym. Sci.,

Polym. Chem. Ed., 18, $1267(1980) \mathrm{b}$

OVERBERGER, C.G. and MORISHIMA, Y.: J. POlym. Sci.,

Polym. Chem. Ed., 18, $1433(1980) \mathrm{C}$

PHOTAKI, I.: J. Am. Chem. Soc., 85, 1123 (1963)

PITHA, J.: Polymer, 18, 425 (1977)

SAEGUSA, T., IKEDA, H., and FUJII, H.: Polym. J., 3 , 35 (1972)

SHOMSHTEIN, Z.A. and GILLER, S.A.: Chem. Heterocyclic Comp. , 12, 27 (1976)

TAKEMOTO, K. and INAKI, Y.: Adv. Polym. Sci., 41,1 (1981)

Received September 14, accepted September 24, 1981 